Subscribers to Psyche are entitled to borrow from the Library any work which could be replaced in case of loss, upon compliance with the simplest conditions practicable. In every way the Club will be actuated by the most liberal motives.

A Permanent Publication Fund has been established by the Club, but it is yet too small to insure the continuance of the publication of Psyche. The Club does not hesitate to ask the friends of Entomology to contribute to this Fund, believing that the Bibliographical RECord is too important to deserve discontinuance. Should this fund be secured, North American Entomologists will have the satisfaction of possessing a current analysis of the literature of their own department more carefully prepared and more promptly issued than any which the students of other departments possess.

The second volume of Psxche will extend from January, 1877 to December, 1879. The subscription price in North America is three dollars for the volume; foreign subscriptions are the equivalent of fourteen shillings sterling; which must be paid in advance to the editors.

Address: Editors of Psyche, Cambridge, Massachusetts, U. S. A.

\title{
The Tube-Constructing Ground-Spider of Nantucket.
}

In my rambles over the Island of Nantucket, I frequently noticed circular holes in the ground and sometimes stopped to probe them with a blade of beach grass or a slender twig; astonished to find how straight and deep they were, and once or twice "feeling a bite" at the end of my probe, I determined to ferret out the spider which I was sure inhabited them. I started out one morning in the middle of September, armed with an old hoe and a brass shoe-horn, which proved the most serviceable of tools, to a point where I had seen an unusual number of holes. Selecting a good sized hole in the sand, with no plant near by, I first tested its depth and then, leaving the grassblade in the tube, dug a deeper hole about a decimetre distant, and scraping away the sand from the first hole laid it open from top to bottom. I was rewarded by the discovery at the bottom 
of the tube - a depth of nearly two decimetres - of an enormous spider guarding a cocoon of eggs nearly as large as herself. Although I worked all day and laid open more or less perfectly some dozen holes, securing a spider in nearly every one, this proved to be my greatest prize, as no other specimen possessed an egg-cocoon. The general result of these excavations and captures enables me to present a somewhat full account of the history of the species, although many points still need to be investigated.

The soil of Nantucket is always more or less sandy. This spider digs its holes in almost any open place, but it seems to prefer the sandiest spots and to choose not indeed the loosest soil but the flat spots in the neighborhood of the sanddunes by the sea-shore; it is exceedingly common. about Coatue; it may be found in the loose sand of the dunes themselves, but in such cases ordinarily seeks the protection of a bunch of beach grass. My only excavations have been upon and in the neighborhood of these sand-dunes, but the holes probed in other parts of the island in the firmer soil proved nearly or quite as deep. The holes are always cylindrical, perfectly simple and very nearly, generally quite, vertical; at the summit they are funnel-shaped to a scarcely perceptible extent, the narrowest portion being at from a quarter to half a centimetre from the surface of the ground, in the holes of the full-grown insects; below this they increase pretty regularly and very slightly in diameter to a depth of from $1 \frac{1}{2}$ to nearly 5 decimetres, the largest being nearly 20 millimetres in diameter; only one spider is found in a single tube. The accompanying table gives the size of the only five of which I took careful measurements. The figures are in millimetres.

$\begin{array}{ccccc}\text { No. } & \text { Depth. } & \text { Width at top. } & \begin{array}{c}\text { Width near } \\ \text { middle. }\end{array} & \begin{array}{c}\text { Width at } \\ \text { bottom. }\end{array} \\ 1 & 167 & 10 & 19 & 22 \\ 2 & 263 & 9 & 12 & 14 \\ 3 & 270 & 15 & 18 & 26 \\ 4 & 205 & 13 & 16 & 19 \\ 5 & 103 & 4 & 7 & 10\end{array}$

The "width at top" was taken at the very mouth of the tube, no notice being taken at the time of the slight diminution in diameter just below the mouth. Nos. 3 and 4 were in rather 
looser sand than the others, and in the middle of the upper half of No. 3 the diameter was only $9.6 \mathrm{~mm}$. No. 5 was occupied by a spider partially grown, but perhaps would have been deeper if a short root of some plant had not lain in the way of any further direct progress. No. 1 was occupied by the female with egg-cluster, and was considerably enlarged at the bottom to allow for the additional burden. The holes are large enough to allow the spider to turn itself around, for a specimen made to enter a hole head foremost was dug out and found head upward.

Holes were found only two millimetres in diameter at the top and correspondingly shallow, from a quarter to a half a decimetre deep; the shallowest, therefore, scarcely reach the moister sand which lies beneath the surface. All the tubes are lined throughout with silk, but this is only apparent in the smallest holes; the silk is invariably more abundant in the superficial layer of dry soil, where it is doubtless more needed; examination with a lens shows that it continues to the bottom of the deepest holes also. The portion surrounded by dry sand may, with care, be removed uninjured; even here, however, the web has no rigidity, and though grains of sand and splinters and fragments of grass-blades adhere to it, it collapses as soon as it is removed, being unable to support its own weight. At the edge of the opening of the tube, little straws and sticks are not infrequently interwoven with the silk, apparently to form a better protection, and, in a road through the woods, I once found a hole where the entrance was marked by a little pile of sticks crossing each other at all angles, but leaving the opening perfectly circular, surrounded by a raised rampart nearly twenty millimetres high.

In excavating the tubes, I took pains to examine carefully the debris at their bottom, and to remove this until I was sure I had reached the virgin sand. In one I found a matted, soggy mass of insect remains mingled with sand; among other things I noticed a large-winged locust, apparently a Trimerotropis, a medium-sized Carabid, and a Necrophorus; in another the only recognizable object was the shard of a small lamellicorn beetle; in a third (a small hole) only a little fly; in a fourth the remains of a Lycosa itself; perhaps fragments of the cast-off skin 
of the proprietor; while in a fifth, the bottom was filled to the depth of twenty millimetres or more with numerous insects mingled with sand, among which I could distinguish five or six Carabidae of different species, other beetles and a sand-wasp. These remains were always buried in the sand, never lying loose upon the surface; from their nature, as well as from the increasing size of the tubes in passing downward, it would seem as if most, though certainly not all, of the insects eaten had fallen into the tube. Judging from the number of spiders seen outside their holes, and from the sluggishness at night of specimens I had imprisoned for some time, the spiders are apparently diurnal, and not nocturnal.

On teasing one of these spiders with a straw moved up and down gently in its hole, and at the same time gradually withdrawn, the spider may be made to come very near the surface of the ground, but in no instance did I succeed in coaxing one within sight. While poking at one, a little fellow in a tube about a couple of decimeters off came up to the top of his burrow, evidently to see what all the disturbance was about, and remained crouching, so that the front of his head and his bent legs were just on a level with the ground. When one is removed from its hole it will feign death, but when put at bay it shows a vicious ferocity; raising the whole anterior part of its body, with jaws wide apart and front legs threateningly raised, it will jump at objects thrust near it, and strike them forcibly and repeatedly with its fangs.

As already remarked, I kept several of these spiders for a time. One of them was a female I had dug out of her hole at Coatue, with about twenty young on her back; these mostly adhered to her abdomen, but at times ran all over her, even upon the smooth surface of her denuded cephalothorax. Occasionally they would leave the mother, wander about and then return; jarring the vessel in which they were kept did not disturb them, whether on or off their mother's back, nor could I induce them by any device to return to their mother before they chose. It is plain that they leave the mother early and immediately make burrows for themselves, for I found living in minute tubes spiders no larger than those still remaining upon 
their mother's back. I did not measure these young spiders, but they could not have exceeded two millimetres in length, and evidently were at most but a few weeks old.

Most of my experiments in feeding were made with this mother; she would capture and eat an unlimited number of flies. They were always caught by a rapid movement of the the first (and occasionally the second) pair of legs and of the palpi, sweeping the victim in toward her cheliceres; once between these, there was no escape ; they were squeezed until the juices could be seen to exude, were turned over and over, squeezed again, and finally dropped. To see what the creature would do if an insect came in her way while she was feeding, I put other flies into the enclosure, after she had been sucking one for twenty minutes. In an instant she was on the alert, raising herself partially upon her legs and placing the front pair and palpi in position; at the first opportunity another fly was seized and stowed away beside the first; a third and fourth were shortly added and the whole horrid mass rolled over and over for fresh squeezes for an hour or more. When these were dropped I offered her some more, and although her appetite must have been appeased, she seized them with the same avidity, attacking them much as if she were possessed of some venomous spite against them, all astir if she missed one, and never tiring of fresh prey. Again she enfolded four carcasses in her capacious jaws, but the attempt at a fifth caused her to drop one, which she did not seek to regain. She squeezed them only a short time (proving that she was not very hungry), then dropped them, and the young ones ran down their mother's legs, and after foraging for a while found them; whether they were attracted by the odor of food, or some signal was given by the mother, I cannot say, but they had been remaining quiet, almost immovable, upon her back for nearly twentyfour hours, and only now left her protection. After this they roamed and returned at will and without concert, and once I saw the mother with a freshly caught fly in the grasp of her deadly cheliceres, while one of the little ones was seated upon the lower end of the fly sharing in the meal.

After eating, the spider cleans its jaws by thrusting the tips 
of the palpi between the tips and the apical claws of the cheliceres, parting the cheliceres at the same time; and then closing all, draws them out again to repeat the process indefinitely.

The specimens found by me in September, are of four sizes - the full-grown, the medium sized, the small ones and those just hatched. The sizes of the holes correspond. The difference however between the two larger sizes is not great, nor is that between the two smaller, and in either case they run together to a certain extent; it seems probable therefore that the spider is double-brooded and hibernates quite young and when nearly mature.

This spider has been referred to the genus Lycosa, though it differs from it in the greater length of the lowest row of eyes, resembling in this respect a Pirata. The species of the latter group, however, have very different habits, being found by the borders of ponds and running over the surface of the water.

A description of the species, which appears to be new, is appended.

Lycosa arenicola nov. sp. Cephalothorax high and squarely appressed in front, pretty strongly compressed anteriorly, though convex on the sides, being three quarters as high as broad; posterior half expanded and depressed, sloping from the centre regularly and rapidly in every direction except in front, and leaving the hind border regularly rounded; the whole blackish castaneous, castaneous in a longitudinal median band, which is broad on the anterior and narrow on the posterior half, smooth, and covered, but not profusely, with short, delicate, silky, recumbent, gray hairs, mingled with coarser and fulvous hairs on the very face and around the eyes; the anterior half, and especially the crown, with long, black, curving, slender, erect bristles, directed forward and rather sparsely scattered over the surface, least abundant and shortest on the lower half of the sides. Sternum nigro-castaneous with long, distant, erect, black, bristly hairs. Lowest series of eyes of equal length with the middle series, the middle eyes of the lowest series slightly larger than the outer ones, not more than half the diameter of those of the middle or upper series; eyes of lowest series midway between the lower margin of the cephalo- 
thorax and the middle series, and twice as far from the former as their own width; whole ocellar field of about equal breadth and height. Mandibles black, the inner surface and inner border of front surface covered scantily with long black hairs, the rest of the front and onter surface with short fulvous, mixed with a few long black hairs; longer than their common breadth, the extremity with three triangular pointed teeth on either side of the closed fang; the latter pretty strong, nearly half as long as the mandible, black, growing blackish castaneous toward the tip. Legs and palpi luteo-castaneous, the first two pair of legs a little duskier, the whole covered with short recumbent ashen-gray hairs (giving the legs a grayish-brown appearance) and scattered long black hairs, the former supplanted by short blackish-gray hairs on the lower surface and the lower half of the sides of the tibiæ and tarsi of the first two pair of legs, and on the under surface of the tarsi of the last two pair of legs and of the apical half of the palpi; a few black, straight, spinous bristles are scattered over all the femora and tibiæ. Abdomen ashy clay-brown above, with a few scattered black hairs, and a conspicuous black or blackish, irregular median band, extending from near the base to the very tip, sub-continuous in a narrow median stripe, and as a whole made up, on different segments, of transverse subcrescentic spots twice as broad as long, convex forward, with furcate lateral tips; the broadest of these, from one third to one fourth the width of the abdomen, occurs just in advance of the middle of the abdomen, and there is but one large crescent in front of and distant from this, but midway between them is a transverse crescentic line; on the posterior half of the abdomen, the median line is sometimes obliterated, and the contiguous crescents, becoming united at their tips, enclose paler spots. Beneath, the abdomen is nigro-fuscous, and on the sides bears a very broad, obliquely-curving blackish band, extending from the middle of the sides at the base to the vulva, becoming faint and narrow toward the latter. [Description from about a dozen females.]

Measurements of a large specimen. Length $22 \mathrm{~mm}$.; of cephalothorax $10 \mathrm{~mm}$; breadth of same in front $5 \mathrm{~mm}$.; of 
same behind $6.5 \mathrm{~mm}$; height of cephalothorax $3.5 \mathrm{~mm}$.; length of abdomen $12.8 \mathrm{~mm}$; breadth and height of same $8.2 \mathrm{~mm}$.; length of mandibles $4.75 \mathrm{~mm}$; of claw $2.2 \mathrm{~mm}$; of palpi $10.5 \mathrm{~mm}$.; of first pair of legs $25 \mathrm{~mm}$.; of second pair 23.5 $\mathrm{mm}$.; of third pair $21.5 \mathrm{~mm}$.; of fourth pair $28 \mathrm{~mm}$.

The young on the parent's back differ from the adult in having a broader dorsal stripe upon the abdomen, giving them the appearance of being dark above, with silvery sides; they are about as long as the last joint of the third pair of legs.

The egg cocoon is an irregularly spherical mass, $8 \mathrm{~mm}$. in average diameter, of a pale bluish gray color, smooth in some parts, rough in others; it is attached by a thick silken cord to the abdomen of the mother, being grasped by the hinder pair of mammillæ.

Samuel H. Scudder.

\section{BIBLIOGRAPHICAL RECORD.}

The date of publication, here given in brackets [ ], marks the time at which the work was received by the Editor, unless an earlier date of publication is known to him. An asterisk * before a title is the Recorder's certificate of accuracy of quotation. Corrections of errors and notices of omissions are solicited. - B. Pickman Mann.

(Continued from Vol. I, page 216.)

The Proceedings of the American Academy of Arts and Sciences, vols. ix and xi (ser. 2, vols. $i$ and iii) contain nothing entomological; vol. x (ser. 2, vol. ii) contains No. 716 .

* 716. S. H. Scudper. Historical Sketch of the Generic Names proposed for Butterflies: a Contribution to Systematic Nomenclature. p. 91-293. [April, 1875.]

Decision, founded upon historical evidence and given canons of systematic nomenclature, concerning the validity of each name proposed for a genus of butterflies and the species to be considered as typical of each genus; discussion of some principles of nomenclature; attempt to fix the dates of Hübner's different works and of Doubleday and Westwood's Genera of Diurnal Lepidoptera. Discusses about 1104 names; Acentrocneme (Feld.) and Lethites appear for the first time as generic names.

The Proc. Bost. Soc. Nat. Hist. [See Rec., Nos. 173-182], vol. xvii, from p. 257, contain Nos. 717 to 728 .

* 717. S. H. Scudder. Notes on Orthoptera from Northern Peru, collected by Prof. James Orton. p. 257-282. [March, 1875.]

Enumerates 46 species, including two not from Peru. Describes Gryllo- 

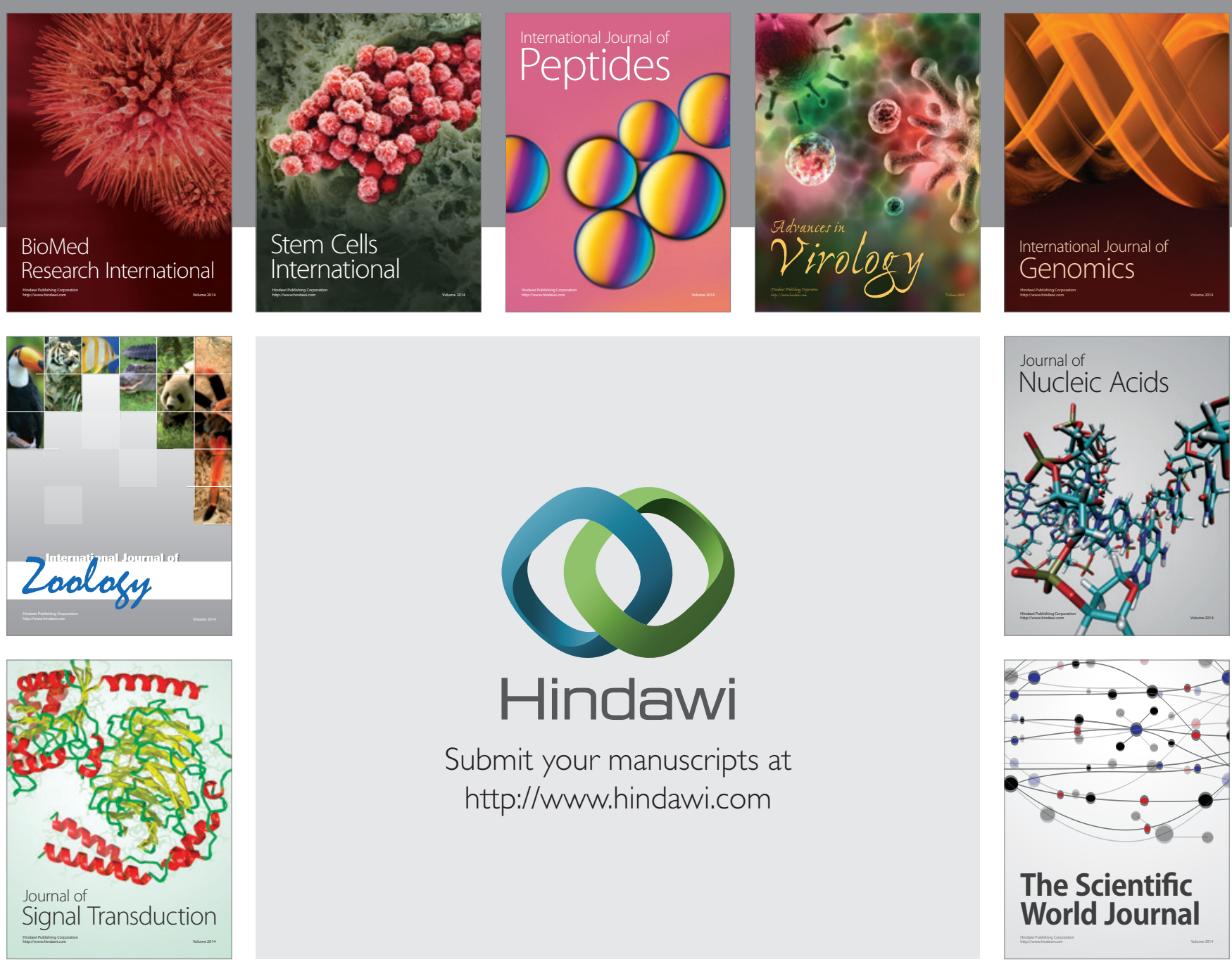

Submit your manuscripts at

http://www.hindawi.com
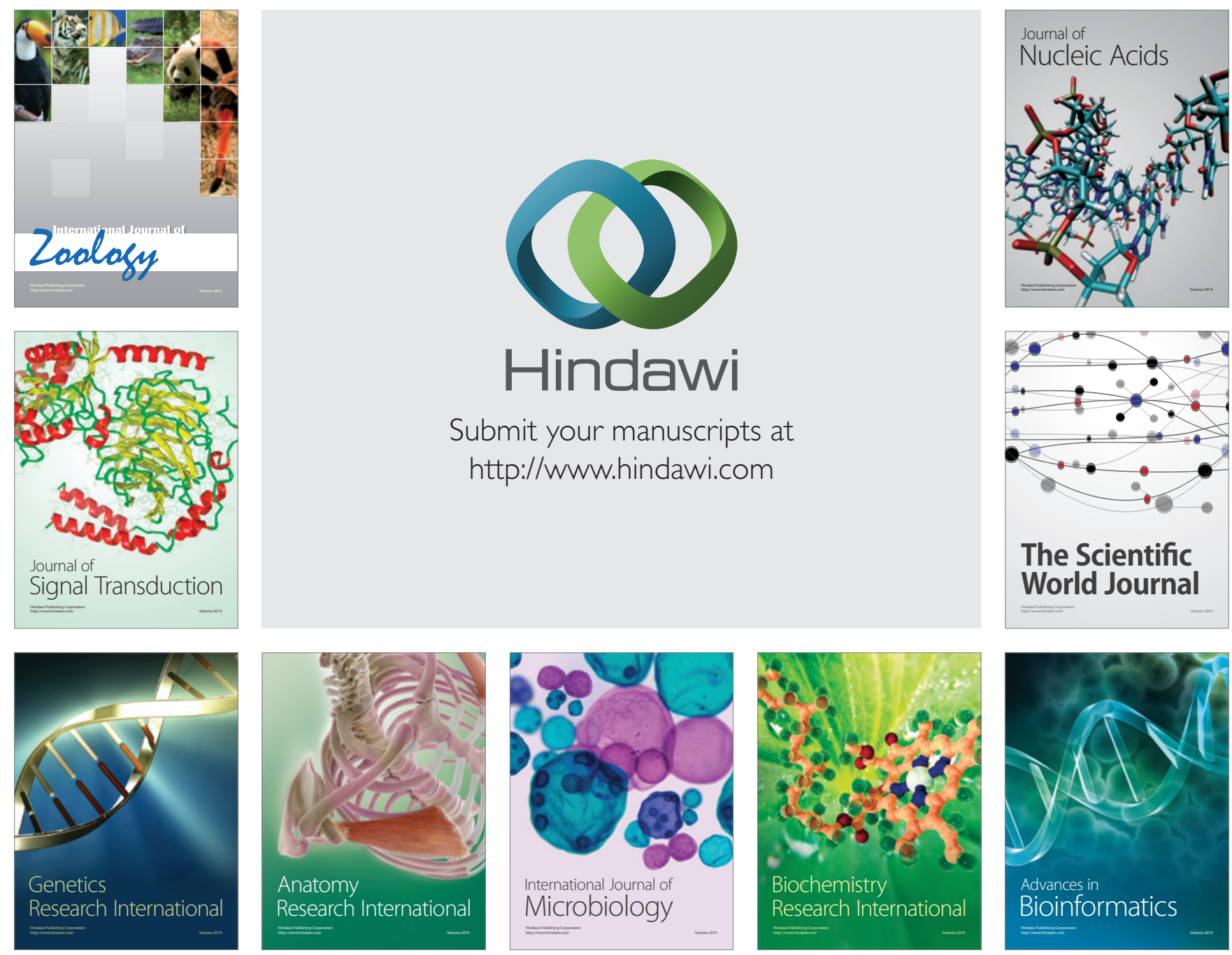

The Scientific World Journal
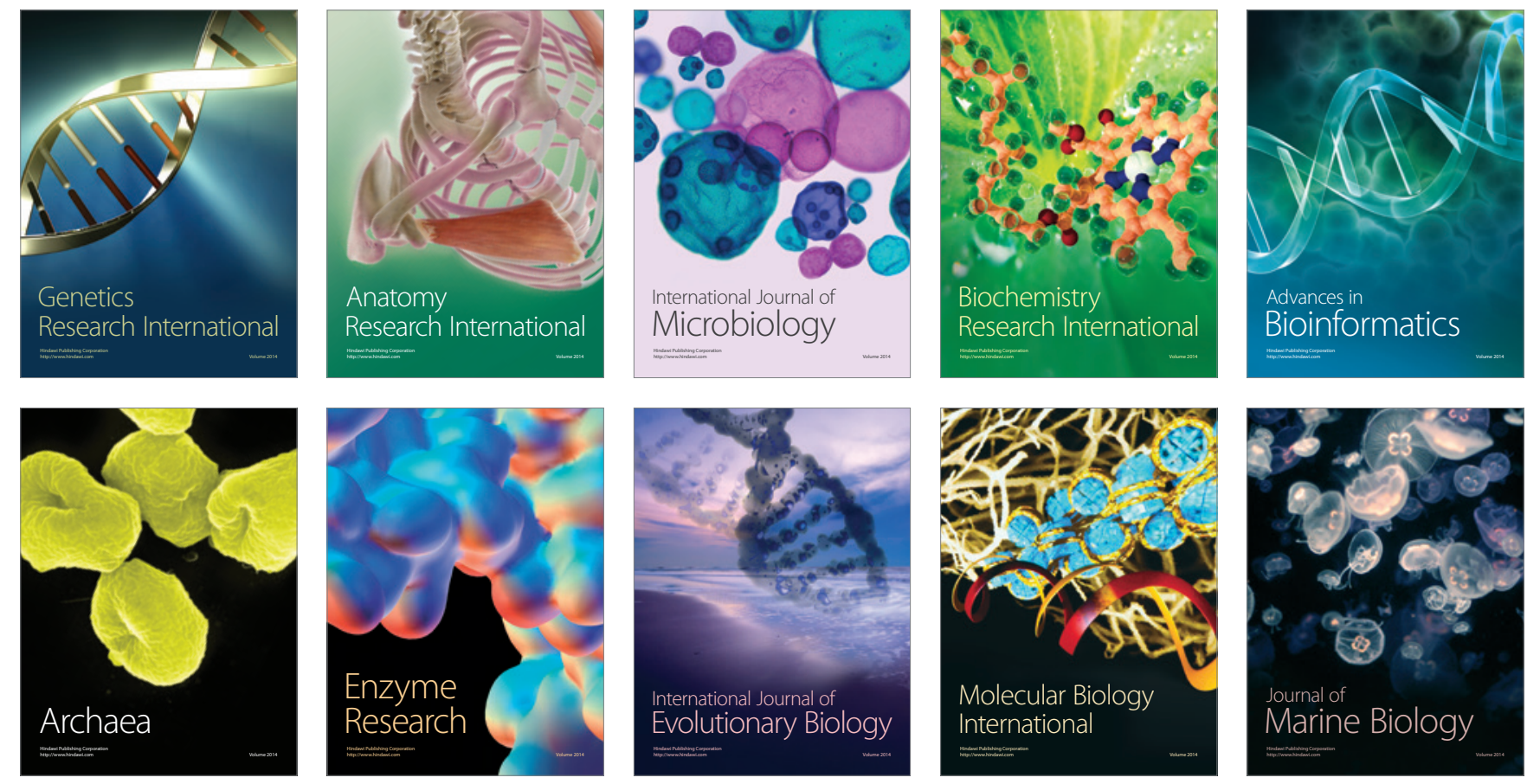